\title{
CALIBRATION OF SIXTY-FIVE 35-YELLOW LOVIBOND GLASSES $^{1}$
}

\author{
By Irwin G. Priest, Deane B. Judd, K. S. Gibson, and Geraldine K. Walker ${ }^{2}$
}

\section{ABSTRACT}

This report deals with 65 nominally 35 -yellow Lovibond glasses collected from members of the American Oil Chemists' Society, submitted to the Bureau of Standards in August, 1927, by H. P. Trevithick, and identified by AOCS numbers engraved on the glasses. It is understood that Mr. Trevithick has a key to these numbers showing the ownership of each glass.

The fundamental standard to which the values here reported are referred is contained implicitly in a particular set of glasses obtained directly from the Lovibond establishment (The Tintometer (Ltd.)) in 1912, kept at the Bureau of Standards, and designated as B. S. 9940 for purposes of identification. The units of the red and yellow scales effective in the present calibration are as derived from this set of glasses by Priest and Gibson in 1927 after adjusting the inconsistencies among the different glasses in the set.

The data reported include, for each glass: (1) The equivalent in terms of standard Lovibond yellow and red; (2) the sunlight transmission.

Explicit directions are given for using the equivalents in practice. Special comments are made on seven glasses having strikingly abnormal transmissions or badly marred surfaces. Also, to aid in the possible identification of the origin of the glasses, detailed information is given as to engraved marks found on the glasses, thickness of the glasses, and character of the edges.

The average equivalent for all of these glasses is 32.3 yellow 0.17 red. The average sunlight transmission is 3.5 per cent higher than the transmission adopted as standard for 35 yellow. It is, however, only 0.6 per cent higher than the standard transmission proper to the average yellow numeral (32.3) found for these glasses, which shows that, in the average, the data for sunlight transmissions

1 This is one of a series of papers dealing with standardization of Lovibond glasses by the Bureau of Standards. Previous publications have been:

1. Gibson, Harris, and Priest, A Spectrophotometric Analysis of the Lovibond Glasses, B. S. Sci. Paper No. 547; February, 1927.

2. Judd and Walker, A Study of 129 Lovibond Red Glasses with Respect to the Reliability of Their Nominal Grades, Oil and Fat Industries, 5, pp. 16-26; January, 1928.

3. Priest and Gibson, Standardizing the Red and Yellow Lovibond Glasses, J. Opt. Soc. Am. and Rev.

Sci. Inst., 16, p. 116; February, 1928.

4. Priest, Tests of Color Sense of A. O. C. S. Members and Data on Sensibility to Change in Lovibond Red, Oil and Fat Industries, 5, pp. 63-73; March, 1928.

5. Judd, Effect of Temperature Change on the Color of Red and Yellow Lovibond Glasses, B. S. Jour. Research, 1 (RP31), pp. 859-866; November, 1928.

The present paper is one of the results of a cooperative investigation by the bureau and the American Oil Chemists' Society, one of the authors (Walker) being an employee of that society detailed to the bureau as a research associate, September 12, 1927, to July 2, 1928. Monthly reports of progress on this cooperative work have been published in Oil and Fat Industries as follows: December, 1927, pp. 433-435; January, 1928, pp. 27-29; February, 1928, pp. 58-59; March, 1928, pp. 92-94; A pril, 1928, pp. 114-117; May, 1928, pp. 152156; June, 1928, pp. 184-188 (there are many misprints in this report); July, 1928, pp. 220-221; August, 1928, pp. 247-250; and September, 1928, p. 278.

2 The authors have had the assistance of Mabel E. Brown and J. O. Riley in observing and computing. $30442^{\circ}-29-1$ 
and yellow-scale numerals are in accord. The maximum errors found in the collection are:

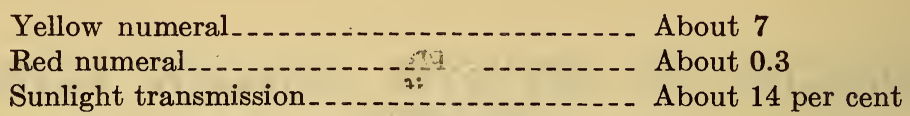

The sunlight transmission of one of the glasses (AOCS No. 125) is quite remarkably higher (12 per cent) than the standard transmission for 35 yellow. The sunlight transmissions of six glasses (AOCS Nos. 27, 31, 41, 97, 125, and 131) depart notably (9 to 14 per cent) from the transmissions proper to the yellow numerals assigned to them in this calibration.

It is clear that the average equivalent of these 65 glasses is not in precise accord with the standard 35 yellow derived by Priest and Gibson from the Bureau of Standards set (B. S. 9940) obtained from the Lovibond establishment. On the other hand, the discrepancy is certainly not more than two or three times the least difference perceptible with certainty by the best observers under the most favorable conditions of observation. The idea occurs that it might seem reasonable to adopt the average as standard instead of the standard which has been adopted. There are, however, grave objections to this proposal, as explained in the report.

Of course, if their own average were taken as standard instead of the standard arbitrarily adopted, the "errors" for most of the glasses would be notably decreased. With a very few possible exceptions, the uniformity of these glasses is quite as good as could be required or expected in order to comport with the purposes and methods of use for which they were intended by the makers. The irregularities found and reported here have only been discovered by methods of observation greatly exceeding in sensibility and accuracy the methods of color matching contemplated by the makers, and the methods actually used by the oil chemists in grading oils.

The surfaces of three glasses (AOCS Nos. 41, 97, and 119) were so badly marred that it might seem advisable to discard them. With the possible exception of these badly marred glasses, all of the glasses are considered fit to be regarded as equivalent to standard 35 yellow under the present customary conditions of grading oils. The point to this recommendation is not that the glasses are perfect from the point of view of precision calibration, but that the errors found are negligible in comparison with the uncertainties inherent in the customary methods of using the glasses. When more reliable and precise methods of grading are adopted, it will be in order to consider using the precise equivalents which are given for each glass. Of course, even under present conditions, the glasses which approach more nearly standard 35 yellow may perhaps be regarded with somewhat greater satisfaction and respect by those who use them. The detailed data given in Table 1 of the report will enable such glasses to be identified.

An outstanding result of this investigation is the conclusion that the discrepancies of color grading which have troubled the oil trade can not be charged to lack of uniformity among the 35-yellow glasses. The sources of these troubles are rather to be sought in the following factors:

1. Unstandardized, nonuniform, and insensitive methods of comparing the oil samples with the glasses.

2. Grading of oil by observers having abnormal color sense or low power of hue discrimination.

3. Errors in the red glasses.

It seems just to assume that this rather large collection of glasses constitutes a fair sample of 35-yellow glasses issued by the Lovibond establishment and in use in the oil trade in the United States. If this be admitted, it seems superfluous to 
test individual 35-yellow glasses further under present conditions. The chance of finding one with an error great enough to be of consequence in comparison with the other uncertainties just mentioned is very small. After the above-mentioned sources of error have been eliminated in nractice, it will be due season to reconsider the calibration of 35-yellow glasses ii it then appears necessary. In the meantime it may well be considered legitimate to accept on faith the 35-yellow glasses as issued by the Lovibond establishment.

\section{CONTENTS}

I. Description of glasses.

II. Relation of character of the glasses to accuracy of calibration _._._- 798

III. Standards and units .

1. Standard glasses and derivation of units ............. 798

2. Colorimetric specification of standard 35 yellow

3. Physical specification of standard 35 yellow

4. Actual glass standard for 35 yellow

IV. Fundamental principles and methods of calibration._.

V. Special methods of calibration used in the present case_....... 803

1. Empiric formula for sunlight transmission

2. Empiric formula for yellow-scale numeral_.......... 805

3. Apparatus and methods for the direct comparison of the colors of the standard and the glasses being tested . . 807

4. Determination of red correction .

VI. Synopsis of results of calibration

1. Sunlight transmission.

2. Red and yellow equivalents

3. Application to the color grading of oil

VII. General conclusions_._. 818

\section{DESCRIPTION OF GLASSES}

These glasses were submitted by H. P. Trevithick, president of the American Oil Chemists' Society, in August, 1927. They are to be identified by the engraved initials, AOCS, followed by a number which refers to the individual glass, as shown in Column I of Table 1. It is understood that nearly all of these glasses were collected from members of the A. O. C. S., and that Mr. Trevithick has preserved a key by which the ownership of each glass can be found from its identification number. Nearly all of these glasses had been in use for some time. Very few new glasses were included. Engraved marks found on the glasses have been carefully noted and are cited as precisely as possible in Column IX of Table 1. It will be noticed that there are four distinctly different styles of labels and many minor variations. As further information, which might be of interest and possible service in resolving questions as to the origin, age, and history of the individual glasses, we give also in Table 1 the thicknesses of the glasses (Column $\mathrm{X}$ ) and notes on the character of the edges (Column XI). 
TABLE 1.-Summary

\begin{tabular}{|c|c|c|c|c|c|c|c|c|c|c|c|}
\hline \multirow{2}{*}{$\begin{array}{c}\text { Aocs } \\
\text { No. }\end{array}$} & \multicolumn{2}{|c|}{$\begin{array}{c}\text { Color Qual1tity } \\
\text { Equivalents }\end{array}$} & \multicolumn{5}{|c|}{ Sun11ght Trangm19810n } & \multirow{2}{*}{ 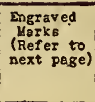 } & \multirow{2}{*}{$\begin{array}{l}\text { Thickness } \\
\text { In } \\
\begin{array}{l}\text { oll11- } \\
\text { meters }\end{array}\end{array}$} & \multirow{2}{*}{ 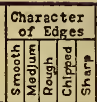 } & \multirow{2}{*}{ 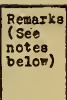 } \\
\hline & 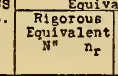 & 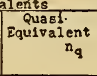 & $T_{0}$ & $\mathrm{~T}_{\mathrm{D}}$ & $\frac{\frac{T_{D}-T_{D}}{T_{0}}}{\text { per cent }}$ & 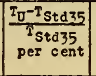 & \begin{tabular}{|l|}
$\frac{p_{0}-T_{y m}}{p_{0}}$ \\
per cent
\end{tabular} & & & & \\
\hline $\mathrm{I}$ & $\mathrm{II}$ & III & IT & $\nabla$ & $\overline{\nabla I}$ & $\mathrm{PII}$ & VIII & $\mathrm{Ix}$ & $x$ & $+7 x$ & \begin{tabular}{|l|l|l|}
$\mathrm{XII}$ \\
\end{tabular} \\
\hline \begin{tabular}{r|}
5 \\
58 \\
12 \\
13 \\
14
\end{tabular} & $\begin{array}{l}31.27+0.13 \mathrm{R} \\
30.4+.16 \\
30.0+.26 \\
31.4+.14 \\
33.4+.19\end{array}$ & $\begin{array}{r}35 x+0.058 \\
+.088 \\
+.16 \\
+.06 \\
+.15\end{array}$ & $\begin{array}{r}0.666 \\
: 663 \\
: 657 \\
: 607\end{array}$ & $\left|\begin{array}{r}0.6331 \\
: 6303 \\
: 6253 \\
: 6146\end{array}\right|$ & $\begin{array}{l}+0.5 \\
+2.1 \\
-0.5 \\
+1.5 \\
-1.3\end{array}$ & $\begin{array}{l}+5.4 \\
+5.6 \\
+1.6 \\
+5.6 \\
+5.6 \\
+0.6\end{array}$ & $\begin{array}{l}+1.4 \\
+1.7 \\
-3.7 \\
+1.2 \\
-1.8\end{array}$ & $\begin{array}{l}\hat{\Lambda} \\
\hat{\Lambda}_{1} \\
\hat{\Lambda}_{2}\end{array}$ & $\begin{array}{l}2.12 \\
\text { 3.1.0 } \\
2.02 \\
2.13 \\
3.06\end{array}$ & $\left|\begin{array}{l}x \\
x \\
x \\
x\end{array}\right| x$ & \\
\hline \begin{tabular}{l|}
15 \\
15 \\
22 \\
22 \\
27 \\
27
\end{tabular} & $\begin{array}{l}31.0 \pm: 22 \\
31.5 \pm: 10 \\
33.6 \pm: 15 \\
33.2 \pm: 09 \\
39.2 \div .06\end{array}$ & \begin{tabular}{|l}
+.14 \\
$+: 04$ \\
$+: 13$ \\
$+: 05$ \\
$+: 14$
\end{tabular} & $\begin{array}{l}: 609 \\
: 642 \\
: 692 \\
: 649 \\
: 649\end{array}$ & $\begin{array}{l}.6344 \\
: 6626 \\
: 655 \\
: 6562 \\
.6505\end{array}$ & $\begin{array}{l}-4.1 \\
+0.9 \\
+0.5 \\
+1.4 \\
-0.2\end{array}$ & $\begin{array}{l}+0.9 \\
+6: 4 \\
+4.3 \\
+6: 9 \\
+7.6\end{array}$ & 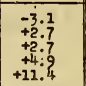 & $\begin{array}{l}\hat{A}_{1} \\
\hat{A}_{1} \\
\hat{A}_{1} \\
B^{2}\end{array}$ & $\begin{array}{l}2.99 \\
2.17 \\
2.99 \\
3.99 \\
2.85\end{array}$ & \begin{tabular}{|l|l|l|}
$x$ & $x$ \\
$x$ & $x$ & \\
$x$ & $x$ & $x$ \\
\end{tabular} & o \\
\hline \begin{tabular}{l|l}
31 \\
32 \\
37 \\
41 \\
42 \\
4
\end{tabular} & \begin{tabular}{|l}
$37.4+.04$ \\
$33.5 \pm: 11$ \\
$28.9 \pm: 22$ \\
$32.8 \pm: 12$ \\
$29.6+19$ \\
$2.6+19$
\end{tabular} & $\begin{aligned}+.08 \\
+09 \\
+09 \\
+10 \\
+08 \\
+09 \\
\end{aligned}$ & $\begin{array}{r}.663 \\
629 \\
6613 \\
: 557 \\
629\end{array}$ & $\begin{array}{l}: 6626 \\
: 6507 \\
65613 \\
: 6449 \\
: 6270\end{array}$ & $\begin{array}{r}0.0 \\
-0.3 \\
-2.9 \\
-24.9 \\
+0.1 \\
+0.3\end{array}$ & $\begin{array}{l}+9.9 \\
+4.9 \\
+1.6 \\
-1.7 \\
+4.7 \\
\end{array}$ & $\begin{array}{l}+11.9 \\
+1+2 \\
+4.6 \\
-4.7 \\
-9.6 \\
-1.4 \\
\end{array}$ & $\begin{array}{ll}B & b \\
A_{3} & \\
A_{2} & \\
\Lambda_{1} & \\
\end{array}$ & $\begin{array}{l}2.92 \\
2.64 \\
2.36 \\
2.90 \\
1.96\end{array}$ & \begin{tabular}{|l|l} 
\\
$x$ \\
$x$ \\
$x$
\end{tabular} & $\alpha$ \\
\hline $\begin{array}{l}43 \\
46 \\
50 \\
51 \\
56\end{array}$ & $\begin{array}{l}30.0+.22 \\
31.9 \pm: .27 \\
30.8 \pm \div .22 \\
32.7 \pm: 25 \\
30.2+.27\end{array}$ & 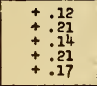 & $\begin{array}{l}: 624 \\
: 609 \\
: 598 \\
: 607 \\
: 605\end{array}$ & $\begin{array}{l}.6245 \\
: 62028 \\
: 6202 \\
: 56703 \\
.6103\end{array}$ & $\begin{array}{l}-0.1 \\
+0.7 \\
-3.6 \\
-3.6 \\
-0.7 \\
-0.8\end{array}$ & $\begin{array}{l}+3.4 \\
+0.6 \\
+0.9 \\
+0.6 \\
+0.3\end{array}$ & $\begin{array}{l}-1.8 \\
-2.5 \\
-5.1 \\
-1.7 \\
-4.7\end{array}$ & $\begin{array}{l}A_{1} \\
A_{4} \\
D^{2} \\
A_{1}\end{array}$ & $\begin{array}{l}2.64 \\
2.28 \\
2.11 \\
2.42 \\
3.03\end{array}$ & $=F^{x} x$ & \\
\hline \begin{tabular}{l|l}
57 \\
61 \\
62 \\
63 \\
71
\end{tabular} & \begin{tabular}{|l|}
$30.3+20$ \\
$30.5 \pm: 14$ \\
$32.6 \pm 0.08$ \\
$20.2 \pm: 14$ \\
$34.3+.13$
\end{tabular} & 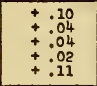 & $\begin{array}{l}.637 \\
.637 \\
6648 \\
: 644 \\
.645\end{array}$ & $\begin{array}{l}.6226 \\
: 6300 \\
: 6224 \\
: 6294 \\
: 6266\end{array}$ & $\begin{array}{l}+2.3 \\
+1: 1 \\
+4.3 \\
+2.3 \\
+3.4 \\
+3.4\end{array}$ & $\begin{array}{l}+5.6 \\
+5.6 \\
+7.4 \\
+6.7 \\
+7.4\end{array}$ & $\begin{array}{l}+0.6 \\
+0.6 \\
+4.8 \\
+0.6 \\
+6.5 \\
+6.5\end{array}$ & 㑷 & $\begin{array}{l}2.83 \\
2.79 \\
1.90 \\
3.21 \\
3.12\end{array}$ & & \\
\hline \begin{tabular}{l|}
75 \\
776 \\
78 \\
83 \\
83
\end{tabular} & $\begin{array}{l}35.1 \pm .08 \\
34.3 \pm .26 \\
31.2 \pm .26 \\
32.2 \pm .26 \\
30.5+.24\end{array}$ & 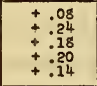 & $\begin{array}{l}.633 \\
: 590 \\
609 \\
: 594 \\
.615\end{array}$ & $\begin{array}{l}.6263 \\
: 5623 \\
: 6078 \\
: 6075 \\
: 6214\end{array}$ & $\begin{array}{l}+1.1 \\
+0.14 \\
+0.2 \\
-2.2 \\
-1.2 \\
-1.0\end{array}$ & $\begin{array}{l}+4.9 \\
-2.2 \\
+0.2 \\
-1: 5 \\
+1.9\end{array}$ & $\begin{array}{l}+4.9 \\
-2.28 \\
-2.9 \\
-4.9 \\
-2.3\end{array}$ & 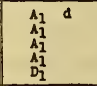 & $\begin{array}{l}3.02 \\
3.20 \\
3.07 \\
2.80 \\
2.41\end{array}$ & $\left|\begin{array}{l}x \\
x \\
x \\
x \\
x\end{array}\right|$ & \\
\hline $\begin{array}{l}84 \\
94 \\
997 \\
996 \\
99\end{array}$ & $\begin{array}{l}30.0+: 24 \\
31.1 \pm: 26 \\
32.4 \div: 02 \\
32.6 \pm: 11 \\
33.8+11\end{array}$ & 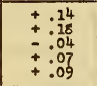 & $\begin{array}{l}.633 \\
.620 \\
: 555 \\
: 645 \\
.641\end{array}$ & $\begin{array}{l}.6199 \\
: 6047 \\
: 6406 \\
: 6368 \\
: 6304\end{array}$ & $\begin{array}{r}+2.3 \\
+2.5 \\
-2.5 \\
+1.7 \\
+1.8 \\
+1.7\end{array}$ & $\begin{array}{l}+4.9 \\
+2.9 \\
+8.0 \\
+7.0 \\
+6.4 \\
+6.2\end{array}$ & $\begin{array}{r}-0.3 \\
-1.3 \\
-10.3 \\
+4: 3 \\
+4.9\end{array}$ & $\begin{array}{l}A_{1} \\
A_{6} \\
A_{1} \\
A_{1} \\
B_{1}\end{array}$ & $\begin{array}{l}2.87 \\
2.59 \\
2.13 \\
2.65 \\
2.85\end{array}$ & {$\left[\begin{array}{l}x \\
x\end{array}\right]_{x}^{x} x_{x}^{x}$} & $\alpha \beta \gamma$ \\
\hline $\begin{array}{l}100 \\
101 \\
102 \\
103 \\
109\end{array}$ & $\begin{array}{l}29.8+.23 \\
34.5 \pm: 11 \\
33.3 \pm: 26 \\
36.3 \pm: 12 \\
28.8+.20\end{array}$ & $\begin{array}{l}+.13 \\
+09 \\
\vdots 22 \\
\vdots 16 \\
+.08\end{array}$ & $\begin{array}{l}.622 \\
.6631 \\
665 \\
.612 \\
.635\end{array}$ & $\begin{array}{l}.6078 \\
: 6282 \\
.5892 \\
: 62727 \\
.6270\end{array}$ & $\begin{array}{l}+2.3 \\
+0.4 \\
+2.5 \\
-0.1 \\
+1.3\end{array}$ & $\begin{array}{l}+3.1 \\
+4: 6 \\
+0.3 \\
+1: 4 \\
+5.3 \\
+5.3\end{array}$ & $\begin{array}{l}-2.3 \\
+4.0 \\
-1.0 \\
+3.4 \\
-1.1\end{array}$ & 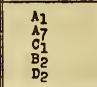 & $\begin{array}{l}2.68 \\
2.84 \\
3.04 \\
3.11 \\
2.85\end{array}$ & $\left|\begin{array}{l|l}x \\
x \\
x\end{array}\right| x$ & \\
\hline $\begin{array}{l}110 \\
114 \\
115 \\
119 \\
119\end{array}$ & $\begin{array}{l}31.5 \pm .19 \\
34.6 \pm .13 \\
29.2 \pm .20 \\
30.0+23 \\
33.9+.11\end{array}$ & 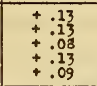 & $\begin{array}{l}.632 \\
.612 \\
.635 \\
.608 \\
.617\end{array}$ & $\begin{array}{l}: 61644 \\
: 61644 \\
: 6294 \\
: 6274 \\
.6276\end{array}$ & $\begin{array}{l}+2.5 \\
-0.7 \\
+0.9 \\
-2.1 \\
-1.1\end{array}$ & $\begin{array}{l}+4.8 \\
+1.4 \\
+5.4 \\
+0.3 \\
+2.3\end{array}$ & $\begin{array}{l}+1.1 \\
+1: 0 \\
+0.9 \\
-4.3 \\
+1.1\end{array}$ & 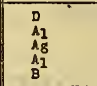 & $\begin{array}{l}2.56 \\
3.99 \\
2.45 \\
2.56 \\
3.35\end{array}$ & $x x_{x}^{x} \times x$ & $\beta$ \\
\hline $\begin{array}{l}125 \\
125 \\
130 \\
131 \\
135\end{array}$ & $\begin{array}{l}37.4 \div: 01 \\
230.9 \div: 15 \\
30.1 \div: 20 \\
27.9 \div: 18 \\
35.2 \div .18\end{array}$ & $\begin{array}{l}+.03 \\
\vdots: 05 \\
\vdots 010 \\
\vdots 04 \\
+0.18\end{array}$ & $\begin{array}{l}.666 \\
: 647 \\
: 617 \\
.592 \\
640\end{array}$ & $\begin{array}{l}6573 \\
: 670 \\
: 6189 \\
: 6270 \\
6300\end{array}$ & $\begin{array}{l}+3.0 \\
+3.0 \\
+-3.3 \\
-5.6 \\
+1.6\end{array}$ & $\begin{array}{l}+12.12 \\
+7.2 \\
+2.3 \\
-1.9 \\
+6.1\end{array}$ & $\begin{array}{r}+14.0 \\
+1.8 \\
-2.8 \\
-9.8 \\
+6.1\end{array}$ & $\begin{array}{l}B \\
\text { A } \\
A_{11} \\
A_{2}^{10} \\
D_{2}\end{array}$ & $\begin{array}{l}3.02 \\
2.85 \\
2.80 \\
2.55 \\
2.98\end{array}$ & $\mid$\begin{tabular}{l|l}
$x$ \\
$x$ \\
$x$ \\
$x$ \\
$x$
\end{tabular} & 8 \\
\hline $\begin{array}{l}137 \\
140 \\
141 \\
146 \\
148\end{array}$ & \begin{tabular}{|l}
$34.1+.11$ \\
$32.4 \div: 21$ \\
$34.0 \div: 19$ \\
$33.0 \pm: 19$ \\
$33.5 \div .03$
\end{tabular} & $\begin{array}{l}+.99 \\
\vdots \\
+13 \\
\vdots 17 \\
+15 \\
+.06\end{array}$ & $\begin{array}{l}.645 \\
.604 \\
636 \\
.619 \\
.638\end{array}$ & $\begin{array}{l}6300 \\
: 6163 \\
: 62635 \\
: 61531 \\
6331\end{array}$ & $\begin{array}{l}+2.4 \\
-1: 0 \\
+1: 6 \\
+1: 2 \\
+0.8\end{array}$ & $\begin{array}{l}+6.9 \\
+0.1 \\
+5.4 \\
+2.4 \\
+5.8\end{array}$ & $\begin{array}{l}+5.8 \\
-3.5 \\
+4.5 \\
+0.5 \\
+4.1\end{array}$ & $\begin{array}{lll}B & \\
C_{2} & 0 \\
A_{1} & \\
A_{4} & \end{array}$ & $\begin{array}{l}2.91 \\
2.88 \\
2.86 \\
3.37 \\
3.35\end{array}$ & \begin{tabular}{|l|l|l|l|}
$x$ & $x$ & $x$ \\
$x$ & $x$ & $x$ & $x$ \\
$x$ & $x$
\end{tabular} & \\
\hline $\begin{array}{l}150 \\
1558 \\
153 \\
156 \\
157\end{array}$ & $\begin{array}{l}31.1 \pm .05 \\
33.4 \div: 20 \\
32.6 \pm 07 \\
29.9 \pm: 25 \\
33.6+10\end{array}$ & $\begin{array}{r}7.03 \\
\vdots 16 \\
\vdots 103 \\
\vdots .15 \\
+.08 \\
\end{array}$ & $\begin{array}{l}.651 \\
668 \\
657 \\
6607 \\
: 632 \\
\end{array}$ & $\begin{array}{l}6581 \\
: 6054 \\
: 6599 \\
: 6558 \\
6257 \\
\end{array}$ & $\begin{array}{l}+2.1 \\
+0.1 \\
-0.1 \\
-1.7 \\
-1.7 \\
+1.0\end{array}$ & $\begin{array}{l}+7.9 \\
+6.8 \\
+5.8 \\
+0.9 \\
+4.8 \\
+4.8\end{array}$ & $\begin{array}{l}+3.7 \\
-0.8 \\
+6.8 \\
-4.6 \\
+3.2 \\
+3.2\end{array}$ & $\begin{array}{l}A_{8} \\
\hat{A}_{11} \\
\hat{\Delta}_{1} \\
B_{3}\end{array}$ & $\begin{array}{l}1.64 \\
2.77 \\
2.69 \\
2.29 \\
3.37 \\
\end{array}$ & $x \int_{x}^{x} \times x x_{x}^{x} \times \frac{x}{x}$ & \\
\hline \begin{tabular}{l|}
155 \\
162 \\
165 \\
166 \\
191 \\
\end{tabular} & 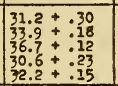 & 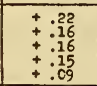 & $\begin{array}{l}.619 \\
.665 \\
.608 \\
.616 \\
639\end{array}$ & $\begin{array}{l}60222 \\
: 65252 \\
: 6171 \\
: 6237 \\
6257\end{array}$ & $\begin{array}{l}+2.7 \\
+1.1 \\
-1: 5 \\
+0.4 \\
+2.1\end{array}$ & $\begin{array}{l}+2.6 \\
+5.3 \\
+0.5 \\
+2.1 \\
+5.9\end{array}$ & $\begin{array}{l}-1.3 \\
+4.3 \\
+2.4 \\
-2.4 \\
+2.9\end{array}$ & $\begin{array}{l}A_{2} \\
D_{2} \\
A_{12} \\
A_{1} \\
A^{2}\end{array}$ & $\begin{array}{l}2.64 \\
22.96 \\
2.92 \\
2.93 \\
1.87\end{array}$ & $\left(\begin{array}{l|l}x \\
x \\
x \\
x \\
x\end{array} \mid x\right.$ & \\
\hline A1B.Yeen & $32.26+.167$ & +.112 & & & +0.23 & +3.5 & +0.62 & & 2.77 & & \\
\hline
\end{tabular}


Notes referred to in Column IX of Table 1

\section{ENGRAVED MARKS ON THE GLASSES (Presumably Engraved by the Maker)}
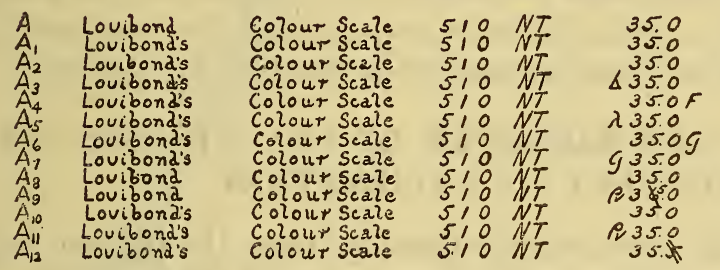

England

$\begin{array}{llll}B & 510 & N T \\ B_{1} & 51 & N T \\ B_{2} & 510 & N T \\ B_{3} & 510 & N T \\ B_{4} & 510 & N T\end{array}$

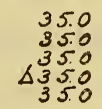

YLutiond's colourScale
$z$

$\begin{array}{ll}C & \text { Lovibond's } \\ \mathcal{C}_{1} & \text { Lutbond's } \\ \mathcal{C}_{2} & \text { Lovibond's }\end{array}$

Colour Scale
Colour Scale
Colour Scale

$\begin{array}{lll}510 & \pi T \\ 5,0 & \pi T \\ 510 & 17 T\end{array}$

3.509
$3.0 \%$
35.0

$\begin{array}{ll}D & 6 \\ D_{1} & 8 \\ D_{2} & \text { o }\end{array}$

Reg'd. No.
Peg'd. Wo.
Regid. No.

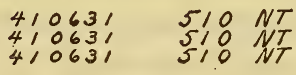

350

England

England 3.5

\section{Notes}

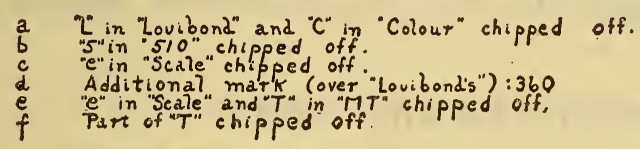


All of these glasses depart, many quite markedly, from one or more of the following ideal conditions which are highly desirable for precision color standards: (1) Planeness of surfaces; (2) parallelism of surfaces; (3) freedom from haze, pits, and scratches on the surfaces; and (4) freedom from striæ and bubbles.

The following glasses were particularly bad in the respects noted: (1) Haze, AOCS Nos. 41, 97, 119; (2) scratches, AOCS Nos. 15, 41, 97, 98, 103, 116, 119; (3) striæ, AOCS Nos. 27, 31, 43, 98; and (4) waviness of surface, AOCS No. 114.

The type of spectral transmission with which we are dealing and the extent of its variation among the present lot of glasses are shown in Figure 1. The much-confused and widely divergent continuous curves were plotted from the data on spectral transmission of 23 individual glasses, about half of which are included in the present lot. The circles and $\times$ marks indicate, respectively, the maximum and minimum transmissions found among the present lot of 65 glasses.

\section{RELATION OF CHARACTER OF THE GLASSES TO ACCURACY OF CALIBRATION}

With glasses having such imperfections as these, the highest degree of precision and reliability in calibration is out of the question. An analogous situation would arise if we should attempt a precision calibration of an ordinary wooden foot rule with its crudely marked divisions. No arnount of tedious scientific measurement could make of the wooden rule a length standard comparable with a finely ruled steel, quartz, or platinum-iridium precision standard. In the present instance we have done our best to calibrate the glasses submitted, but in considering this report one must not lose sight of the character of the material concerned. The uncertainties remaining in the present results are largely inherent in the nature of the glasses themselves; to attempt to reduce them by further measurements or observations would be quite futile. ${ }^{3}$

\section{STANDARDS AND UNITS}

\section{STANDARD GLASSES AND DERIVATION OF UNITS}

The fundamental standard to which the values here reported are referred is contained implicitly in a particular set of glasses obtained in 1912 directly from the Lovibond establishment (The Tintometer (Ltd.)), now kept at the Bureau of Standards, and designated as B. S. 9940 (Bureau of Standards inventory number). ${ }^{4}$ The units

\footnotetext{
3 These remarks are not to be interpreted as an unqualified condemnation of the Lovibond glasses. The scratches, pits, and haze have probably resulted from careless usage. As supplied by the Lovibond establishment, these glasses serve a useful purpose to the extent that their characteristics permit; but, as implied above, they are comparable to the common weights and measures of trade rather than to the precision weights and measures of the scientific laboratory.

${ }^{4}$ See B. S. Sci. Paper No. 547.
} 


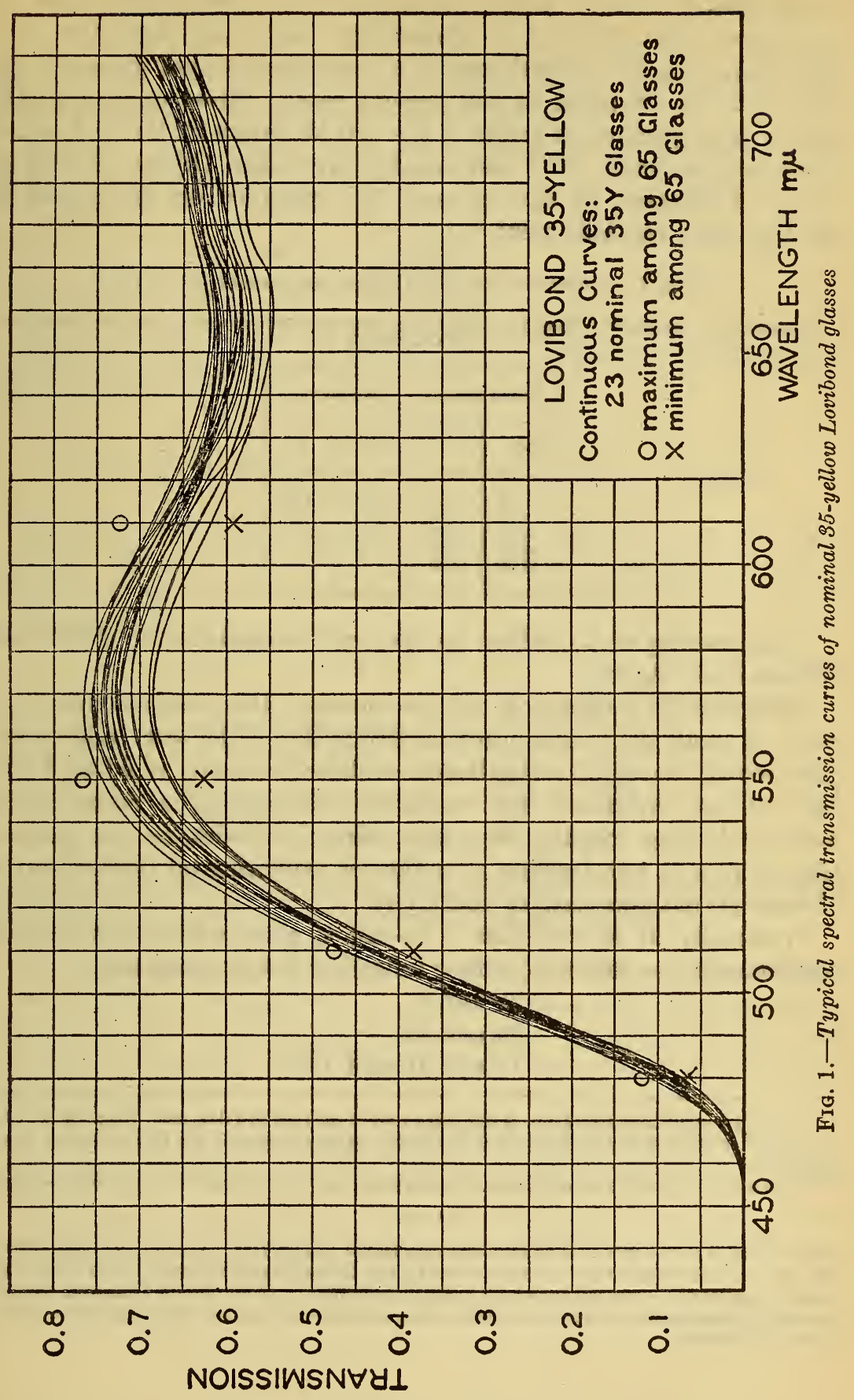


of the red and yellow scales effective in the present calibration are as derived from this set of glasses by Priest and Gibson in 1927 after adjusting the inconsistencies among the different glasses in the set. For the purposes of the present report, these units are sufficiently well specified in terms of the actual glasses by Table 2, which gives the numerals $\left(\mathrm{N}^{\prime \prime}\right)$ assigned by Priest and Gibson to selected glasses designated by the numeral $(\mathrm{N})$ engraved on the glasses by the Lovibond establishment. ${ }^{5}$

TABLE 2.-Bureau of Standards Lovibond glasses, B. S. 9940

[Numerals $\left(\mathrm{N}^{\prime \prime}\right)$ assigned by Priest and Gibson to glasses assigned the numeral $(\mathrm{N})$ by the Lovibond establishment]

\begin{tabular}{|r|r|c|c|}
\hline \multicolumn{2}{|c|}{ Yellow glasses } & \multicolumn{2}{|c|}{ Red glasses } \\
\cline { 2 - 3 } $\mathrm{N}^{\prime \prime}$ & \multicolumn{1}{|c|}{$\mathrm{N}$} & $\mathrm{N}^{\prime \prime}$ & $\mathrm{N}$ \\
\hline & & & \\
\hline 1.19 & 1.0 & 0.104 & 0.02 \\
2.07 & 2.0 & .199 & .13 \\
5.07 & 5.0 & 1.17 & 1.0 \\
10.05 & 10.0 &. & \\
20.86 & 20.0 & & \\
\hline
\end{tabular}

The meaning of 35 yellow on the scale established by Priest and Gibson is as follows:

Theoretically (neglecting, for the moment, the possible cumulative effect of small errors and practical difficulties of the test), a 35-yellow glass would match 35 unit glasses combined so as to avoid all loss of light at the interfaces (for example, cemented by a nonabsorbing: medium having exactly the same refractive index as the glasses). However, it is not feasible to make an experimental demonstration of such an extreme case of additivity.

Practically, it is true that a 35-yellow glass will be matched by combinations as follows (surface reflection being eliminated):

\section{0 and 5}

20 and 15

10 and 10 and $15 .^{6}$

B All red and yellow numerals given in this paper refer to the scale of Priest and Gibson, except where it is clearly apparent from the context that Lovibond's engraved numeral, the nominal grade, is being referred to.

${ }^{6}$ In general, the principle on which the scale is constructed may be expressed by the additivity condition,

$$
S_{1}=S_{2}
$$

where $S_{1}$ and $S_{2}$ are the sums of the scale numerals attached, respectively, to two combinations of glasses such that (1) they contain equal numbers of glass plates (glasses of zero absorption being introduced if needed), and (2) they evoke the same color under like conditions. In this form of statement, specifying that the two combinations shall contain equal numbers of plates takes the place of specifying the elimination of surface reflections. 


\section{COLORIMETRIC SPECIFICATION OF STANDARD 35 YELLOW}

The colorimetric specifications (with Abbot-Priest sun ${ }^{7}$ as neutral) adopted by Priest and Gibson to represent the $35 \mathrm{Y}$ derived from the above-mentioned set of glasses are as follows:

Trilinear Coordinates ${ }^{8}(r, g, b)$ on the basis of excitations ${ }^{9}$ given by the O. S. A. colorimetry committee: ${ }^{10}$

$$
\begin{aligned}
& r=0.5017 \\
& g=0.4611 \\
& b=0.0372
\end{aligned}
$$

Sunlight transmission $(T)$ on the basis of visibility recommended by Gibson and Tyndall: ${ }^{11}$

$$
T=0.6033
$$

\section{PHYSICAL SPECIFICATION OF STANDARD 35 YELLOW}

The above-described standard would be realized to a very close

\begin{tabular}{|c|c|c|}
\hline & Ideal & $\begin{array}{c}\text { From } \\
\text { Table } 3\end{array}$ \\
\hline $\begin{array}{l}\text { } \\
\text { Transmission for sunlight } \\
\text { Purity } \\
\text { Dominant wave length } 1_{-} \text {m }_{\mu_{-}}\end{array}$ & $\begin{array}{r}0.5017 \\
.4611 \\
.0372 \\
.6033 \\
.931 \\
575.66\end{array}$ & $\begin{array}{r}0.5018 \\
.4611 \\
.0371 \\
.6033 \\
.9315 \\
575.66\end{array}$ \\
\hline
\end{tabular}
approximation by a glass having the spectral transmission given in Table 3. The degree of approximation in colorimetric terms is shown as follows:

1 These values of dominant wave length are given to the nearest hundredth of a millimicron, not because they may be computed via the O.S. A. excitations with this absolute accuracy (which is not possible), but because they may be (and have been) computed with this relative accuracy.

The scale numeral of the glass having the spectral transmission shown in Table 3 would be 35.1. One-tenth of a unit is a negligible amount at this point on the yellow scale, inasmuch as the least difference perceptible with certainty has been found to be greater than one unit.

\footnotetext{
7 Phys. Rev. (2), 11, p. 502; 1918. J. Opt. Soc. Am. and Rev. Sci. Inst., 12, p. 479; 1926.

8 J. Opt. Soc. Am. and Rev. Sci. Inst., 9, pp. 506-508; 1924. This paper gives the definition of "trilinear coordinates."

$\because$ 'The excitations used are essentially those referred to in the following footnote. The actual values used are those extrapolated by Priest and Gibson (J. Opt. Soc. Am. and Rev. Sci. Inst., 10, p. 230; 1925).

10 J. Opt. Soc. Am. and Rev. Sci. Inst., 6, p. 549; 1922.

11 B. S. Sci. Paper No. 475, p. 174, Table 3, last column.
}

$30442^{\circ}-29-2$ 
TABLE 3.-Spectral transmission of hypothetical glass approximating closely to standard Lovibond $35 Y$ adopted by Priest and Gibson

\begin{tabular}{|c|c||c|c|}
\hline $\begin{array}{c}\text { Wave } \\
\text { length }\end{array}$ & $\begin{array}{c}\text { Trans- } \\
\text { mission }\end{array}$ & $\begin{array}{c}\text { Wave } \\
\text { length }\end{array}$ & $\begin{array}{c}\text { Trans- } \\
\text { mission }\end{array}$ \\
\hline$m_{\mu}$ & & & \\
450 & 0.0001 & 600 & 0.6618 \\
460 & .0016 & 610 & .6294 \\
470 & .0202 & 620 & .6018 \\
480 & .0795 & 630 & .5777 \\
490 & .1786 & 640 & .5610 \\
& & & \\
500 & .2958 & 650 & .5490 \\
510 & .4215 & 660 & .5471 \\
520 & .5219 & 670 & .5598 \\
530 & .5998 & 680 & .5769 \\
540 & .6535 & 690 & .5810 \\
& & & \\
550 & .6882 & 700 & .5924 \\
560 & .7075 & 710 & .6135 \\
570 & .7110 & 720 & .6391 \\
580 & .7036 & & \\
590 & .6869 & & \\
\hline
\end{tabular}

\section{ACTUAL GLASS STANDARD FOR 35 YELLOW}

We have not been able to find a glass fulfilling the ideal specifications for standard $35 \mathrm{Y}$. We have, however, a two-glass combination, the spectral transmission of which is given by multiplying each transmission in Table 3 by the constant 0.93386 . The trilinear coordinates, dominant wave length, and purity are consequently the same as computed from this table; and the sunlight transmission is $0.93386 \times 0.6033=0.5634$. This combination consists of the two

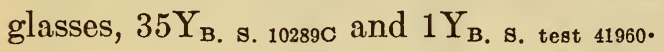

\section{FUNDAMENTAL PRINCIPLES AND METHODS OF CALIBRATION}

The results to be given must be considered in terms of certain fundamental ideas which will now be presented.

A complete description of the color evoked by one of these glasses must comprehend three items (or their equivalents)-hue, saturation, and brilliance. ${ }^{12}$ A perfect standard $35 \mathrm{Y}$ would be correct in all three of these attributes of color and would be characterized by certain values of-

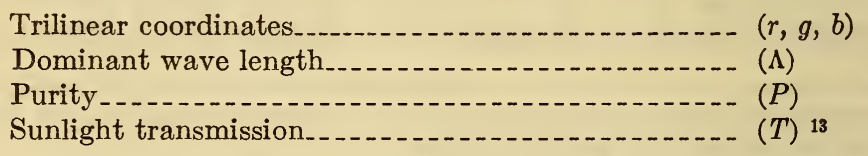

12 Report of the Colorimetry Committee, Optical Society of America, J. Opt. Soc. Am. and Rev. Sci. Inst., 6, pp. 534-535; August, 1922. Separate copies of this report may be purchased at 50 cents per copy of Prof. F. K. Richtmyer, business manager, J. Opt. Soc. Am. and Rev. Sci. Inst., Cornell University, Ithaca, N. Y.

${ }^{13}$ For definitions of these terms, see following papers by Priest: Apparatus for Determination of Color * * * J. Opt. Soc. Am. and Rev. Sci. Inst., 8, pp. 174-176; January, 1924 . Computation of Colorimetric Purity, J. Opt. Soc. Am, and Rev, Sc̣i, Inst., 9, pp. 503-505; November, 1924, 
However, the Lovibond yellow scale is primarily a saturation scale, running from neutral to a very saturated yellow. The outstanding colorimetric variable is purity. The preeminent significance of the yellow numeral is that greater numerals indicate greater saturation determined chiefly by colorimetric purity. Nevertheless, it is also true that dominant wave length and sunlight transmission both change with the yellow numeral. On the scale established by Priest and Gibson certain values of purity, dominant wave length, and sunlight transmission appertain to each value of the yellow numeral.

The fundamental method ${ }^{14}$ of calibrating a yellow Lovibond glass consists essentially of the following steps:

1. The trilinear coordinates $(r, g, b)$, the dominant wave length $(\Lambda)$, the purity $(P)$, and the sunlight transmission $(T)$ are computed from the spectral transmission of the glass.

2. The glass is assigned a yellow-scale numeral proper to its colorimetric purity. ${ }^{15}$

3. The difference between the actual dominant wave length of the glass and the dominant wave length proper to the numeral which has been assigned it is then considered. If this difference is zero, the glass may be regarded as standard in hue. If the difference does not exceed a certain tolerance, the glass may be regarded as practically standard in hue. If the difference is very small but not negligible, it may sometimes be advantageously stated in terms of Lovibond red, as described later.

4. The difference between the actual sunlight transmission of the glass and the transmission proper to the numeral which has been assigned it is then considered. If this difference is zero, the glass is standard in transmission and brilliance. If this difference is not zero, due account may be taken of it in using the glass.

\section{SPECIAL METHODS OF CALIBRATION USED IN THE PRESENT CASE}

As has been pointed out in the preceding section, the fundamental method of calibration requires the complete determination of spectral transmission throughout the visible spectrum followed by elaborate computations. For a large number of glasses (as in the present case), this would be a very laborious and time-consuming task; therefore, certain short-cut methods have been used. These short cuts are based on certain empiric formulas and methods which will now be described briefly.

\footnotetext{
14 As developed by Priest and Gibson.

is The parameter actually used by Priest and Gibson for finding the correct numeral was $1 / b$. The proeedure, however, is equivalent to assigning the glass a numeral in accord with its colorimetric purity.
} 


\section{EMPIRIC FORMULA FOR SUNLIGHT TRANSMISSION}

Adopt symbols as follows:

$T$ is transmission for Abbot-Priest sunlight computed from complete spectral transmission on basis of visibility recommended by Gibson and Tyndall;

$T_{510}$ is transmission for wave length $510 \mathrm{~m} \mu$ (millimicrons);

$T_{550}$ is transmission for $550 \mathrm{~m} \mu$; and

$T_{610}$ is transmission for $610 \mathrm{~m} \mu$.

The following formula ${ }^{16}$ has been shown to hold to a close approximation for 15 nominal ${ }^{17} 35 \mathrm{Y}$ glasses previously investigated:

$$
T=0.0070+0.2456\left(T_{510}+2 T_{550}+T_{610}\right)
$$

Considering all of the data for the 15 glasses from which it was derived (by least-square adjustment), the average error of this formula is $0.0012 T$, and the maximum error in the 15 cases is $0.0029 T$.

As a further check on this formula we have determined the complete spectral transmission for eight glasses in the present lot and have computed the values shown in the following table:

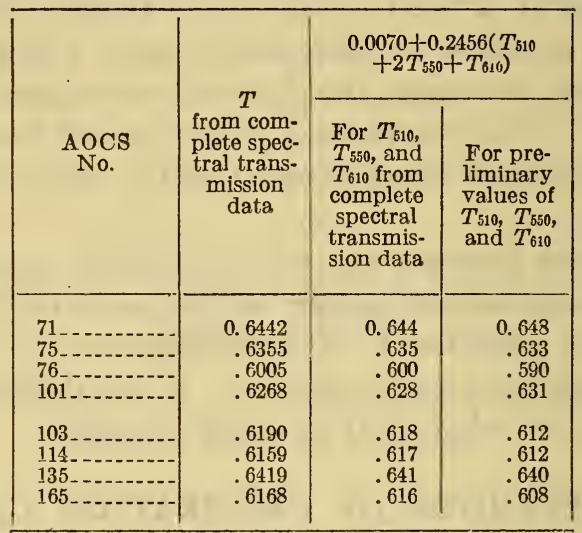

The second column of the above table gives the sunlight transmission as computed by rigorous methods from the complete data on spectral transmission. The two results by the formula (third and fourth columns of above table) are derived from two sets of values for $T_{510}, T_{550}$, and $T_{610}$, namely:

1. Preliminary isolated measurements of $T$ at wave lengths 510 , 550 , and 610 made before the complete spectral transmission dat: were obtained (fourth column). These results have the same status as all of the values given in Column IV of Table 1.

16 Derived and verified by Priest and Judd, July-August, 1927.

${ }_{17}$ That is, 35 according to engraved marks, 
2. Final values as read from the final curve for spectral transmission (third column).

It happens that 3 of the glasses in the present lot of 65 were also included in the lot of 15 previously investigated, and data on their spectral transmission obtained about January, 1927, are thus available. Using these data and the present independent values for $T_{510}, T_{550}$, and $T_{610}$, the values given in the following table have been computed:

\begin{tabular}{|c|c|c|c|}
\hline \multirow[b]{2}{*}{$\begin{array}{l}\text { AOCS } \\
\text { No. }\end{array}$} & \multirow[b]{2}{*}{$\begin{array}{c}T \\
\text { from } \\
\text { complete } \\
\text { spectral } \\
\text { transmis- } \\
\text { sion data }\end{array}$} & \multicolumn{2}{|c|}{$\begin{array}{c}0.0070+0.2456\left(T_{510}+\right. \\
\left.2 T_{550}+T_{610}\right)\end{array}$} \\
\hline & & $\begin{array}{c}\text { For } T_{610} \\
T_{550} \text {, and } \\
T_{610} \text { from } \\
\text { complete } \\
\text { spectral } \\
\text { transmis- } \\
\text { sion data }\end{array}$ & $\begin{array}{l}\text { For inde- } \\
\text { pendent } \\
\text { values of } \\
T_{510} T_{550} \\
\text { and } T_{610} \\
\text { found in } \\
\text { present in } \\
\text { vestigation }\end{array}$ \\
\hline $\begin{array}{l}156 \\
157 \\
158\end{array}$ & $\begin{array}{r}0.6114 \\
.6346 \\
.6224\end{array}$ & $\begin{array}{r}0.611 \\
.634 \\
.621\end{array}$ & $\begin{array}{r}0.607 \\
.632 \\
.619\end{array}$ \\
\hline
\end{tabular}

In either of the two tables just preceding, the differences between the second and third columns show merely specimen errors of the formula itself when using only one set of data. The average error is less than 0.0013T. The differences between the second and fourth columns show the magnitude of errors which may be expected in the values of $T$ given in Column IV of Table 1. The average error is about $0.0078 T$.

From the foregoing presentation it is evident that the error of this empiric formula for sunlight transmission (equation (1)) is negligible.

\section{EMPIRIC FORMULA FOR THE YELLOW-SCALE NUMERAL}

Adopt symbols as follows:

$N^{\prime \prime}$ is the yellow-scale numeral as found (via $1 / b$ ) by the fundamental method;

$T_{480}$ is the transmission for wave length $480 \mathrm{~m} \mu$; and

$T_{550}$ is the transmission for wave length $550 \mathrm{~m} \mu$.

The following empiric formula was derived ${ }^{18}$ from a study of the 15 above-mentioned nominal $35 \mathrm{Y}$ glasses previously investigated:

$$
N^{\prime \prime}=-37.04 \log _{10}\left(T_{480} / T_{550}\right)
$$

Considering all of the data for the 15 glasses from which it was derived (by least-square adjustment), the average error of the formula is 0.23 ; and the maximum error in the 15 cases is 0.83 .

${ }_{18}$ By Priest and Judd; August-September, 1927. 
As a further check on this formula we have also made computations from the complete spectral transmission data for eight glasses from the present lot (the same eight as mentioned in the preceding section). In the following table the results are shown in a manner analogous to the results for transmission in the preceding section $(V, 1)$ :

\begin{tabular}{|c|c|c|c|}
\hline \multirow[b]{2}{*}{$\begin{array}{c}\text { AOCS } \\
\text { No. }\end{array}$} & \multirow[b]{2}{*}{$\begin{array}{l}N^{\prime \prime} \\
\text { from com- } \\
\text { plete spec- } \\
\text { tral trans- } \\
\text { mission } \\
\text { data via } \\
1 / b\end{array}$} & \multicolumn{2}{|c|}{$-37.04 \log _{10}\left(T_{480} / T_{650}\right)$} \\
\hline & & $\begin{array}{l}\text { For } T_{480} \\
\text { and } T_{550} \\
\text { from com- } \\
\text { plete spec- } \\
\text { tral trans- } \\
\text { mission } \\
\text { data }\end{array}$ & $\begin{array}{l}\text { For pre- } \\
\text { liminary } \\
\text { values of } \\
T_{480} \text { and } \\
T_{650}\end{array}$ \\
\hline $\begin{array}{l}71-\ldots-. \\
75--.- \\
76-1 \\
101-.-\end{array}$ & $\begin{array}{l}34.3 \\
35.4 \\
34.2 \\
33.8\end{array}$ & $\begin{array}{l}34.4 \\
35.3 \\
33.5 \\
34.1\end{array}$ & $\begin{array}{l}34.3 \\
35.1 \\
34.3 \\
34.5\end{array}$ \\
\hline $\begin{array}{l}103- \\
114- \\
135 \\
165\end{array}$ & $\begin{array}{l}35.9 \\
33.9 \\
34.3 \\
36.4\end{array}$ & $\begin{array}{l}36.5 \\
34.4 \\
34.9 \\
36.6\end{array}$ & $\begin{array}{l}36.7 \\
34.6 \\
35.2 \\
36.7\end{array}$ \\
\hline
\end{tabular}

Here again the numerals in the second column are those obtained by the more rigorous computation; the third column gives numerals computed by equation (2) taking values of $T_{480}$ and $T_{550}$ from the final complete spectral transmission data; and the numerals in the fourth column (from preliminary values of $T_{480}$ and $T_{550}$ ) have the same status as all values of $N^{\prime \prime}$ in Column II of Table 1.

Likewise, the 3 glasses in the present lot of 65 , also included in the lot of 15 previously investigated, afford spectral transmission data from which the values given in the following table have been computed:

\begin{tabular}{|c|c|c|c|}
\hline \multirow[b]{2}{*}{$\begin{array}{c}\text { AOCS } \\
\text { No. }\end{array}$} & \multirow[b]{2}{*}{$\begin{array}{c}N^{\prime \prime} \\
\text { from } \\
\text { complete } \\
\text { spectral } \\
\text { trans- } \\
\text { mission } \\
\text { data via } \\
1 / b\end{array}$} & \multicolumn{2}{|c|}{$-37.04 \log _{10}\left(T_{480} / T_{650}\right)$} \\
\hline & & $\begin{array}{c}\text { For } T_{480} \\
\text { and } T_{550} \\
\text { from } \\
\text { complete } \\
\text { spectral } \\
\text { trans- } \\
\text { mission } \\
\text { data }\end{array}$ & $\begin{array}{c}\text { For inde- } \\
\text { pendent } \\
\text { values of } \\
T_{480} \text { and } \\
T_{550 \text { found }} \\
\text { in the } \\
\text { present } \\
\text { investiga- } \\
\text { tion }\end{array}$ \\
\hline $\begin{array}{l}156 \ldots \\
157 \\
158\end{array}$ & $\begin{array}{l}30.0 \\
33.1 \\
31.6\end{array}$ & $\begin{array}{l}29.8 \\
33.3 \\
31.4\end{array}$ & $\begin{array}{l}29.9 \\
33.6 \\
31.2\end{array}$ \\
\hline
\end{tabular}

In either of the two tables just preceding the differences between the second and third columns show merely specimen errors of the formula itself when using only one set of data. The average error is 0.34 . The differences between the second and fourth columns show the magnitude of errors which may be expected in the values 
of the yellow numerals $\left(N^{\prime \prime}\right)$ reported in Column II of Table 1. The average error is 0.44 ; the maximum error is 0.9 .

Since the least difference in yellow perceptible with certainty on the $35 \mathrm{Y}+n \mathrm{R}$ scale has been found to be greater than one unit, it appears, from the foregoing presentation of data, that this empiric formula is sufficiently accurate for determining the yellow numeral for all practical purposes.

\section{APPARATUS AND METHODS FOR DIRECT COMPARISON OF THE COLORS OF THE STANDARD AND THE GLASSES BEING TESTED}

The findings which are of chief interest in the present report are derived from the immediate visual comparison of the test glasses with standard glasses. The essential features of the apparatus and method used in this comparison are as follows:

1. The observer conducting the calibration sees, by looking into the Martens photometer, ${ }^{19}$ an illuminated circular field subtending an angle of about $6^{\circ}$ and divided by a vertical diameter.

2. The illumination of both halves of the field is produced by natural north skylight which has been diffused by transmission through a plate of milk glass.

3. Lovibond glasses can be inserted so as to color either half of the field. By placing one glass in the path of the light illuminating one half and another glass in the path of light illuminating the other half, the colors of the two glasses may be compared in immediate juxtaposition.

4. The two halves may be matched in brightness at the will of the observer. If the two glasses are alike in dominant wave length and purity, the adjustment of the brightnesses of the two halves to equality will cause the dividing line to vanish. If, by matching the brightness, by making first one side and then the other brighter, by looking back and forth from one side to the other, and by reversing the positions of the glasses, the observer can perceive no difference in saturation or hue, he concludes that the glasses may be accepted as duplicates in color except that they may have different transmissions.

\section{DETERMINATION OF RED CORRECTION}

As pointed out above, one of the ways in which a $35 \mathrm{Y}$ glass may depart from normal is in regard to its hue. Experience has, indeed, shown that this is the most important error from the practical point of view. The practical import of this circumstance is that the equivalent of a nominal $35 \mathrm{Y}$ glass must usually be given in terms of yellow and red. Thus, of a nominal $35 \mathrm{Y}$ which does not have the

10 The apparatus and methods used have been described in a previous paper, Oil and Fat Industries, 5, pp. 16-18; January, 1928. Naturally, the yellow glass used over the ocular in the previous calibration of red glasses was not used in the present case. 
standard hue for $35 \mathrm{Y}$, but is otherwise normal, we may say that it is equivalent in hue and saturation to $35 \mathrm{Y}+n \mathrm{R}$ or $35 \mathrm{Y}-n \mathrm{R}$, where $n$ is some fraction usually less than 0.3. The meaning of the first equivalent would be that the glass in question was matched (brightness being independently equated) by a standard $35 \mathrm{Y}$ combined with a red glass of numeral $n$. The meaning of the second equivalent would be that the standard $35 \mathrm{Y}$ was matched (brightness being independently equated) by the glass in question combined with a red glass of numeral $n$. In the first case, the error of the glass in question consists in its being reddish relative to the standard. In the second case, the error consists in its being greenish relative to the standard.

The determination of equivalents in this form is, however, complicated by the approximate empiric equivalence of small amounts of red and yellow at $35 \mathrm{Y}$. This equivalence will be discussed later (Section VI, 2).

Let us now consider more closely the problem of finding the yellow and red equivalent of an unknown nominal $35 \mathrm{Y}$ which is not exactly a true $35 \mathrm{Y}$. Let it be assumed that we have a standard $35 \mathrm{Y}$ with which to compare it. The problem will then consist of finding the yellow and red which must be added to (or subtracted from) the standard in order to match the unknown. The following cases may be distinguished:

1. It will be necessary to add only yellow.

2. It will be necessary to add only red.

3. It will be necessary to add both yellow and red.

In the present lot of glasses approximate matches could be found in all cases by adding only red 20 "Quasi equivalents," $n_{\mathrm{q}}$, Column III, Table 1). ${ }^{21}$ It was realized, however, that in some cases we were dealing only with quasi ("make-believe") matches forced by the imposed condition that only red glasses were being added, with the object of obtaining the best practical match that could be obtained subject to this condition. It was apparent that, in these cases, a more satisfactory match would have been obtained by adding yellow (in

20 The striking differences among these glasses appeared to be hue differences:

21 The quasi equivalents were determined by direct comparison, as just described, independently by two observers (DBJ and $\mathrm{GKW}$ ), and all glasses for which these two values differed by more than $0.05 \mathrm{R}$ (11 out of the 65) were retested. Then the quasi equivalents were checked independently by a difierent observer (IGP) using a different method and different apparatus. (For a description of this apparatus, see J. Opt. Soc. Am. and Rev. Sci. Inst., 8, pp. 173-200; January, 1924.) In this method the dominant-wave-length difference between the standard $35 Y$ glass and each test glass was determined and then converted into Lovibond red difference by multiplying by the proper factor (0.5) as determined by previous investigation. Although each înal dominant-wave-length difference was the average of 20 independent settings of the difference, which is about as many settings as entered into the direct determination (by DBJ and GKW) of the quasi equivalents, it was found that the values of quasi equivalent obtained via dominant wave length were not as reliable as those determined directly, due to uncertainties inherent in the method. Hence, in combining the two sets of data, the values of quasi equivalent from direct comparison were given three times the weight of those obtained via dominant wave length. The resulting average values, influenced slightly by the values of rigorous equivalent (to be discussed presently), are recorded in Column III, Table 1. 
addition to the red) either to the standard or to the glass being tested; and these cases were recorded as observations were being made. ${ }^{22}$ However, to have selected by trial and error both the yellow and red requisite to obtain the best match would have been an exceedingly laborious and time-consuming task, almost impossible of accurate execution because of the approximate empiric equivalence of small differences in yellow and small differences in red (Section VI, 2).

This difficulty was circumvented by use of the above-mentioned empiric formula (2) for finding the yellow-scale numeral (Section V, 2). The yellow components $\left(N^{\prime \prime}\right)$ in the "rigorous equivalents" ( $N^{\prime \prime} \mathrm{Y}$ $n_{\mathrm{r}} \mathrm{R}$ ) given in Column II of Table 1 were obtained by this formula from measured values of $T_{480}$ and $T_{550}{ }^{23}$ The red components, $n_{\mathrm{r}}$, in the "rigorous equivalents" $\left(N^{\prime \prime} \mathrm{Y} n_{\mathbf{r}} R\right)$ are to be understood in experimental terms as follows:

1. Direct comparison of glasses is made by means of the Martens photometer as before.

2. The standard $35 \mathrm{Y}$ is placed to cover one half of the field and the glass being calibrated to cover the other half.

3 . On the basis of the yellow-scale numeral already computed for the glass being calibrated ( $N^{\prime \prime}$ of equation (2)), standard yellow glasses ${ }^{24}$ are combined with the standard or with the glass being tested so that the sums of the yellow-scale numerals pertaining, respectively, to the two halves of the field are equal.

4. The field is then scrutinized (brightness being independently adjusted by the observer).

5. If the two halves of the field should seem perfectly matched in all respects, this direct comparison of colors would merely serve as a check on the computed value of $N^{\prime \prime}$, and no red correction would be required. (No such glass was found, however.)

6. If red glasses are required to complete the match, they are added, by trial and error, to one side or the other until a match is found. This correction in Lovibond red units is the red component $\left(n_{\mathrm{r}}\right)$ of the rigorous equivalent $\left(N^{\prime \prime} \mathrm{Y} n_{\mathrm{r}} \mathrm{R}\right)$ recorded in Column II of Table 1.

\footnotetext{
${ }^{22}$ In most of these cases (34 out of 38) it seemed that more yellow should be added to the glass being tested.

${ }^{23}$ In finding the quasi equivalents, notes were made concerning the saturation equivalence (the necessity of adding yellow as mentioned before) of the standard $35 \mathrm{Y}$ and the glass combination being tested. Subsequent analysis of these notes showed them to be in close agreement with the values of $N^{\prime \prime}$ from formula (2); that is, whenever the note was to the effect that the test combination was more saturated than the standard $35 \mathrm{Y}$, it was also true that $N^{\prime \prime}$ was considerably greater (greater by at least three units) than 35; and whenever the note was to the effect that the test combination was less saturated than the standard $35 \mathrm{Y}$, it was also true with but two exceptions that $N^{\prime \prime}$ was smaller (by at least three units) than 35. Furthermore, in obtaining (by the method about to be described) the rigorous red equivalent, $n_{r}$, no saturation differences could be detected in any case. Hence, it may be said that, although $N^{\prime \prime}$ was not determined by direct experimentation, the formula from which it was determined has been verified by extensive direct comparison.

24 Carefully selected to have practically a zero hue error.
} 
The foregoing six steps constitute an idealized description of the procedure leading up to the rigorous red equivalent $\left(n_{\mathrm{r}}\right)$. The values which appear in Column II of Table 1 are not quite the same as those obtained experimentally by this procedure but have been influenced by the experimental values of the quasi red equivalents $\left(n_{\mathrm{q}}\right)$, thus:

In comparing the experimental values of $n_{\mathrm{r}}$ (designated $n_{\mathrm{r}}^{\prime}$ ) with the experimental values of $n_{\mathrm{g}}$ (designated $n_{\mathrm{q}}^{\prime}$ ) it was found that $n^{\prime}{ }_{\mathrm{r}}$ could be computed from $n^{\prime}{ }_{\mathrm{q}}$ with good approximation according to the relation:

$$
n^{\prime}{ }_{\mathbf{r}}=n^{\prime}{ }_{\mathrm{q}}+\left(35-N^{\prime \prime}\right) / 50-0.06
$$

where $N^{\prime \prime}$ is the yellow component of the rigorous equivalent. It was also found true (though not with such good approximation) that

$$
n_{\mathrm{r}}^{\prime}=\Delta \Lambda / 2+\left(35-N^{\prime \prime}\right) / 50-0.13
$$

where $\Delta \Lambda$ is the difference in dominant wave length in millimicrons between each test glass and the standard $35 \mathrm{Y}$ glass.

It is apparent that neither of these two relations which hold approximately for the experimental values $\left(n_{\mathrm{r}}^{\prime}, n^{\prime}{ }_{\mathrm{q}}\right.$, and $\left.\Delta \Lambda / 2\right)$ can apply at all closely to the adopted values $\left(n_{\mathrm{r}}\right.$ and $n_{\mathrm{a}}$ ), because, from its definition, the quasi equivalent $\left(n_{\mathrm{q}}\right)$ is equal to the rigorous red equivalent $\left(n_{\mathrm{r}}\right)$ when the yellow component of the rigorous equivalent $\left(N^{\prime \prime}\right)$ is equal to 35 . We attribute the constants, -0.06 and -0.13 , which should be zero if the true standard $35 \mathrm{Y}$ had been available for all three comparisons, largely to the fact that the standard $35 \mathrm{Y}$ was in these three cases evaluated via three different working standards. ${ }^{25}$ If these three working standards had been correctly evaluated, the constants which actually turned out to be -0.06 and -0.13 would have been nearly zero; hence, it seems reasonable to conclude that the grades of these working standards found by computation from their spectral transmissions are relatively somewhat in error. ${ }^{26}$ This conclusion has been verified independently as follows:

\footnotetext{
25 To obtain the values of $n_{\mathrm{r}}^{\prime}, 35 \mathrm{Y}$ B. S. ${ }_{10280 \mathrm{C}} 1 \mathrm{Y} \mathrm{B.} \mathrm{S.} \mathrm{teat} 41860$ was used; for $n^{\prime}{ }_{\mathrm{q}}, 35 \mathrm{Y}$ Trevithiok B, Gibson No. 5 ; and for $\Delta \Lambda / 2,35 \mathrm{Y}$ B. S. test 41050 .

${ }_{25}$ The extent of the error is not greater than might be accounted for by (1) the measurement of the working standards at different times at unnoted room temperatures, and (2) their imperfect optical nature.

1. A $25^{\circ} \mathrm{C}$. change in temperature has been shown (Judd, B. S. Jour. Research, 1 (RP31), p. 865; November, 1928) to change the color of 35 yellow by an amount equal to $0.2 \mathrm{R}+3 \mathrm{Y}$. The three glasses were measured spectrophotometrically at different times, and experience has shown that a $5^{\circ} \mathrm{C}$. change in the room where the measurements were made often occurs from one day or week to another.

2. Only by repeated extensive measurements can a perfect optical sample be guaranteed correct in spectral transmission to better than 1 per cent throughout. The spectral transmissions of any of these three 35-yellow glasses (except possibly B. S. test 41960 , which has been more carefully measured than the other two) may well be uncertain by 1 or 2 per cent. The total selectivity in a $0.13 \mathrm{R}$ glass (that is, the difference between maximum and minimum transmission) is but 3 per cent. Furthermore, the spectrophotometric data refer to unidirectional illumination of a small area near the centers of the glasses, while the illumination under which these glasses were used as working standardș was diffuse and affected a somẹthat different area,
} 


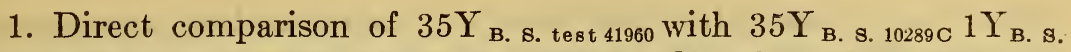
test 41960 by two observers gave an average value of -0.12 as the error in the red correction of the latter relative to the former.

2. A somewhat more indirect comparison of these two standards was afforded by some previous experimental measurements of dominant wave length. By this method the corresponding relative error in the red corrections was obtained as -0.175 .

Although both of these independent determinations $(-0.12 \mathrm{R}$ and $-0.175 R$ ) of the relative error are in good agreement with the error $(-0.13)$ determined indirectly from the grading of these 65 test glasses, neither one is comparable to it in reliability, because neither involves nearly so many readings. The less reliable independent determinations are of value, however, as a closing check.

The relation which the adopted values of $n_{\mathrm{r}}$ and $n_{\mathrm{a}}$ should follow is, therefore-

$$
n_{\mathrm{r}}=n_{\mathrm{q}}+\left(35-N^{\prime \prime}\right) / 50
$$

We have, then, three experimental evaluations of the red component of the rigorous equivalent:

$$
\begin{aligned}
& \text { (a) } n_{{ }_{\mathrm{r}}} \\
& \text { (b) } n_{{ }_{\mathrm{Q}}}+\left(35-N^{\prime \prime}\right) / 50, \text { and } \\
& \text { (c) } \Delta \Lambda / 2+\left(35-N^{\prime \prime}\right) / 50 .
\end{aligned}
$$

However, from the relations already given, we know that the average value from $(a)$ for the 65 glasses is lower than the average value from (b) by 0.06 , which, in turn, is lower by 0.07 than the average value from $(c)$, these differences being ascribable mostly to uncertainty in the evaluation of the working standards. Accordingly, the (a) values $\left(n_{r}^{\prime}\right)$ were all raised, for the purpose of averaging, by 0.06 , while the $(c)$ values (via $\Delta \Lambda$ ) were lowered by 0.07 .

As to the question of weights in taking this average, the $(a)$ values were taken as of two-thirds the importance of the $(b)$ values, because, while the $(a)$ values resulted from an experimental method roughly twice as reliable (due to absence of saturation difference) as that resulting in the $(b)$ values, only about one-third as many readings were involved. The $(b)$ values were taken as of three times the importance of the $(c)$ values for reasons previously discussed. (See footnote 21, p. 808.) The value of $n_{\mathrm{r}}$ (Column II, Table 1) for each glass was, therefore, computed as-

$$
\begin{aligned}
n_{\mathrm{r}}= & 1 / 3\left[n^{\prime}{ }_{\mathrm{r}}+0.06\right]+1 / 2\left[n^{\prime}{ }_{\mathrm{q}}+\left(35-N^{\prime \prime}\right) / 50\right] \\
& +1 / 6\left[\Delta \Lambda / 2+\left(35-N^{\prime \prime}\right) / 50-0.07\right] .
\end{aligned}
$$

The value of $n_{\mathrm{q}}$ for each glass was then computed from equation (3), but the experimental data were so congruent that in no case did the 
value of $n_{\mathbf{q}}$ so computed differ from $n^{\prime}{ }_{\mathbf{q}}$ (experimentally determined) by more than 0.04 . The average absolute value of $\left(n_{\mathrm{q}}-n_{\mathrm{q}}^{\prime}\right)$ was found to be $0.01_{2}$.

\section{SYNOPSIS OF RESULTS OF CALIBRATION}

The essential results of the measurements made on the glasses are shown in Columns II, III, IV, and V of Table 1. Columns VI, VII, and VIII show certain ratios of transmissions (computed from Columns IV and V) which are of interest as criteria of the imperfections of the glasses in their present condition. The remainder of this report will be devoted to explaining these data and pointing out their significance.

\section{SUNLIGHT TRANSMISSION}

Columns IV and V give the sunlight transmission for two different conditions of illumination. $T_{\mathrm{U}}$ (Column IV) is the sunlight transmission for an approximately unidirectional beam incident normal to the face of the glass. ${ }^{27} \quad T_{\mathbf{D}}$ (Column V) is the transmission for diffuse illumination, literally, the ratio of the brightness of a diffusing surface (milk glass) viewed through the glass to the brightness of the same surface viewed directly. ${ }^{28}$ If the glasses were optically clear ${ }^{29}$ plates bounded by perfectly polished plane and parallel surfaces, and if the photometric measurements were free from error, the difference $T_{\mathrm{U}}-T_{\mathrm{D}}$ (and, consequently, the ratio $\left(T_{\mathrm{U}}-T_{\mathrm{D}}\right) / T_{\mathrm{U}}$ ), would be zero. Column VI shows the difference, $T_{\mathrm{U}}-T_{\mathrm{D}}$, in parts per hundred of $T_{\mathrm{U}}$. The departures from zero (plus or minus) are probably due largely to the imperfections of the glasses themselves (scratches, haze, departures of the surfaces from planeness and parallelism), although they may be, in part, due to the unavoidable uncertainties of photometric measurement. The following comments are in order:

1. The very small algebraic average value of $\left(T_{\mathrm{U}}-T_{\mathrm{D}}\right) / T_{\mathrm{U}}(+0.13$ per cent) shows that there is no significant systematic difference between $T_{\mathrm{U}}$ and $T_{\mathrm{D}}$.

2. Values of $\left(T_{\mathrm{U}}-T_{\mathrm{D}}\right) / T_{\mathrm{U}}$ less than 1 per cent may be dismissed without further notice.

3 . If the glasses were to be used (in connection with precise photometric measurements) in grading oils by transmission as well as by hue and saturation, it would be advisable to calibrate more carefully all glasses for which $\left(T_{\mathrm{U}}-T_{\mathrm{D}}\right) / T_{\mathrm{U}}$ is greater than 1 per cent.

4. Under the present customary conditions of using the glasses, no attention need be paid to values of $\left(T_{\mathrm{U}}-T_{\mathbf{D}}\right) / T_{\mathrm{U}}$ less than 10 per cent.

${ }_{27}$ The given values of $T_{\mathrm{U}}$ were computed by formula (1) given in Section $\mathrm{V}, 1$ above.

${ }_{28}$ The given values of $T_{\mathrm{D}}$ were obtained by measuring the transmission of each glass relative to a glass of known transmission. These measurements were made by means of the Martens photometer. The known glass was B. S. 10289B, and its sunlight transmission was taken as 0.6183 .

${ }^{29}$ Free from scratches, haze, and all imperfections causing diffusion of light. 
5. In the two cases (AOCS Nos. 41 and 97 ) in which $\left(T_{\mathrm{U}}-T_{\mathrm{D}}\right) / T_{\mathrm{U}}$ is greater than 10 per cent it is recommended that the glasses be discarded. These large negative values of $\left(T_{\mathrm{U}}-T_{\mathrm{D}}\right) / T_{\mathrm{U}}$ are readily explained by the fact that these glasses are very badly scratched. They are obviously unfit to be used in color grading to which any importance is attached.

Column VII gives the percentage difference between the sunlight transmission of each glass and the sunlight transmission for the standard 35Y. Column VIII gives the percentage difference between the sunlight transmission of each glass and the sunlight transmission proper to the yellow numeral given in Column II. If these glasses are used (in connection with suitable photometric apparatus) to grade oils in terms of transmission as well as hue and saturation, due account should be taken of the data given in Columns VII and VIII. It is noted that the following glasses have strikingly abnormal transmissions: AOCS Nos. 27, 31, 41, 97, 125, 131 (Column VIII). Under the present customary conditions of using the glasses, no attention need be paid to these data.

Incidentally, the algebraic mean of the differences given in Column VIII affords a kind of check on the values of $N^{\prime \prime}$ given in Column II. The argument is as follows: In the average the actual sunlight transmission of these glasses $\left(T_{\mathrm{U}}\right)$ is 0.6 per cent (foot of Column VIII) higher than the transmission proper to the values of $N^{\prime \prime}$ given in Column II. Referring to Figure 15, page 46, Bureau of Standards Scientific Paper No. 547, we readily see that a 10 per cent difference in transmission (that is, a difference of 0.06 at a value of transmission equal to 0.6 ) corresponds to a difference of about 12 in $N^{\prime \prime}$ at this point (32) on the yellow scale. Hence, a difference of 0.6 per cent corresponds to a difference of about 0.7 in $N^{\prime \prime}$. In other words, in the average, the sunlight transmissions found for the glasses check the given values of $N^{\prime \prime}$ to within less than one unit on the yellow scale. At this point on the yellow scale one unit is less than the least perceptible difference. It appears then that if we had obtained $N^{\prime \prime}$ by calibration in terms of sunlight transmission, we would have obtained for all practical purposes the same average value of $N^{\prime \prime}$ as has been obtained by the method actually used to obtain $N^{\prime \prime}$ (equation (2) above)..$^{30}$

\footnotetext{
30 It may be noted that one item of experimental data $\left(T_{550}\right)$ is common to the formula for transmission (equation (1)) and the formula for $N^{\prime \prime}$ (equation (2)). It is therefore in order to inquire whether this circumstance may in itself account for the good agreement just mentioned and render it of no real significance. Assume a positive error in $T_{550}$. Examination of equations (1) and (2) shows that this would result in positive errors in both $T_{\mathrm{U}}$ and $N^{\prime \prime}$. But, we know that the sunlight transmission decreases as the scale numeral increases. It is therefore apparent that an error in $T_{550}$ would prevent the obtaining of concordant results in the computed values of $T_{0}$ and $N^{\prime \prime}$. Hence, it follows that the concordant results obtained are not a mere mathematical necessity due to entering the same item of data $\left(T_{550}\right)$ in the two formulas; on the contrary, concordant results in $T_{\mathrm{U}}$ and $N^{\prime \prime}$ can only be obtained when that item of data is correct.
} 


\section{RED AND YELLOW EQUIVALENTS}

The data in Columns II and III are to be understood as follows:

Brightness being independently equated, the glass designated by AOCS No. in Column I would be accurately matched by the combination of standard yellow and red given in Column II, and approximately matched by the quasi equivalent given in Column III. ${ }^{31}$

These yellow and red equivalents are connected (as stated before) by relation (3) which may be rewritten:

$$
n_{\mathrm{q}}-n_{\mathrm{r}}=\left(N^{\prime \prime}-35\right) / 50
$$

or, stated in words, the difference between the red equivalents is equal to one-fiftieth the difference between the yellow equivalents. From this relation it is apparent that 5 yellow may be, in a sense, substituted for 0.1 red. What is meant by this may be most clearly explained by an experiment. Let the two halves of a photometric field (for example, the Martens photometer field) be perfectly matched at $35 \mathrm{Y}$. Add $0.1 \mathrm{R}$ to one side and match the brightness; there will be a very small but perceptible difference in color. It will be seen that the addition of $0.1 \mathrm{R}$ has made the field redder and more saturated. Remove the red and let the two halves again be perfectly matched at $35 \mathrm{Y}$. Add $5 \mathrm{Y}$ to one side and match the brightness again; there will again be a very small but perceptible difference in color, apparently of much the same nature as before; that is, the addition of $5 \mathrm{Y}$ also makes the field redder and more saturated. In a certain limited sense, then, there is an equivalence between red and yellow. This quasi equivalence is, however, a thing to be warned against rather than a thing to be used. The true meaning of this approximate equivalence may be stated as follows:

Consider a two-part photometric field of which the two halves are, respectively, $35 \mathrm{Y}$ and $40 \mathrm{Y}$. A perfect match would be obtained by adding $5 \mathrm{Y}$ to the first half. Let it be required, however, just as in grading oils on the $35 \mathrm{Y}+n \mathrm{R}$ scale, to obtain the closest approximation to a match possible by adding red and only red. It will be found that adding about $0.1 \mathrm{R}$ gives the best practical approximation to a match. It will readily be admitted that $35 \mathrm{Y}+0.2 \mathrm{R}$ is redder than $40 \mathrm{Y}$ and that $35 \mathrm{Y}$ alone is less red than $40 \mathrm{Y}$. It must also be admitted, however, that $35 \mathrm{Y}+0.1 \mathrm{R}$ does not match $40 \mathrm{Y}$ exactly.

${ }^{31}$ A minus sign preceding the red component indicates that it is to be combined with the test glass (Column I) to match the yellow glass designated in Column II or Column III. The condition of equal brightness may be approximated by combining a plate of clear nonabsorbing glass with the single yellow glass which is being compared with the two-glass combination of yęllow and red. 
As stated before, the addition of $5 \mathrm{Y}$ to $35 \mathrm{Y}$ increases both the redness and the saturation just as the addition of $0.1 \mathrm{R}$ does; but the whole truth includes the statement that the redness increment produced by $5 \mathrm{Y}$ is smaller than that produced by $0.1 \mathrm{R}$, while the saturation increment is larger. Hence, when $40 \mathrm{Y}$ is compared to $35 \mathrm{Y}+$ $0.1 \mathrm{R}$ it seems less red (that is, greener) and more saturated. Moreover, if $7.6 \mathrm{R}$ be now added to both sides, the relative greenness of $40 \mathrm{Y}+7.6 \mathrm{R}$ becomes more obvious. In fact, $35 \mathrm{Y}+7.7 \mathrm{R}$ is not the best practical approximation to a match for $40 \mathrm{Y}+7.6 \mathrm{R}$; indeed the latter is more nearly matched by $35 \mathrm{Y}+7.5 \mathrm{R}$. In other words, the addition of $5 \mathrm{Y}$, which, at $35 \mathrm{Y}$, is the practical equivalent of adding $0.1 \mathrm{R}$, is, on the contrary, at $35 \mathrm{Y}+7.6 \mathrm{R}$ the practical equivalent of subtracting about $0.1 \mathrm{R}$. The fallacy of using, without reservation, the "quasi equivalent," $n_{\mathrm{q}}$, (Column III) for color grading oils should be quite apparent. A true $40 \mathrm{Y}$ glass would have a quasi equivalent of $35 \mathrm{Y}+0.1 \mathrm{R}$ for grading an oil of color about $35 \mathrm{Y}$; but for the purpose of grading an oil of color about $35 \mathrm{Y}+7.6 \mathrm{R}$, the true $40 \mathrm{Y}$ glass would have to be given a quasi equivalent of $35 \mathrm{Y}$ minus an amount (perhaps about 0.1 unit) of red. Thus, the added yellow strength (5Y) which adds to the red strength at $35 \mathrm{Y}$ subtracts from it at $35 \mathrm{Y}+7.6 \mathrm{R}$; furthermore, the amount of this addition or subtraction is not constant but varies along the whole $35 \mathrm{Y}+n \mathrm{R}$ scale. The quasi equivalents, therefore, can not be used for color grading unless $N^{\prime \prime}$ (in the rigorous equivalent) is nearly equal to 35 , and, in this case, the rigorous equivalent may about as well be used, because the two are nearly the same. The values of the quasi equivalents (35Y $n_{\mathrm{q}} \mathrm{R}$, Column III) are included only because they are satisfactory for use in grading oils between $35 \mathrm{Y}$ and $35 \mathrm{Y}+1 \mathrm{R}$. Even for these oils the quasi equivalents become unsatisfactory when $N^{\prime \prime}$ departs too much from 35 , their applicability being questionable when $N^{\prime \prime}$ differs from 35 by more than about three units.

The rigorous equivalent is the strictly correct one; it is applicable to all cases.

\section{APPLICATION 'TO THE COLOR GRADING OF OIL}

The application of the results here given to the practical problem of color grading oil must be considered under two separate headings, viz:

A. Use of glasses under conditions which permit of the highest attainable accuracy.

B. Use of glasses under the present conditions customary in the oil trade. 


\section{These two sets of conditions may be contrasted as follows:}

\section{A}

\section{Conditions permitting of highest attain- able accuracy}

1. Use of a color comparator in which the two fields showing, respectively, the color of the oil and the color of the glasses are viewed in close juxtaposition so that when the fields are matched there is no visible line separating them.

2. Use of a comparator which permits of matching the brightnesses of the two fields by an adjustment independent of the oil and glasses (for example, the Martens photometer).

3 . Rules which permit of varying yellow as well as red so.as to make it possible to obtain a match in saturation as well as hue; that is, a complete color match.

4. Illumination by standard artificial sunlight, with most favorable field brightness.

5. Grading by observers who have been proven normal in their color sense and particularly in their ability to perceive small differences in oolor.
B

\section{Present customary conditions}

1. Use of a color comparator ("tintometer") in which the two fields are separated by a considerable distance or, at least, by a visible coarse line which does not disappear.

2. Use of a color comparator without any device for matching brightness.

3. Arbitrary selection of yellow glass, obtaining closest approximation to match, subject to condition of varying only red.

4. Illumination not standardized with regard to either quality or field brightness.

5. Grading by untested observers.

We now proceed to the discussion of the use of the glasses and the equivalents here given under these two sets of conditions.

\section{A. Conditions of Observation Permitting of Highest Obtainable Accuracy.}

To give a definite example, we will assume an oil sample which may be perfectly matched by yellow between 25 and 45 with the addition of red between 0 and 20 . To obtain the Lovibond equivalent of this oil in red and yellow, proceed as follows:

1. Have at hand the following Lovibond glasses:

One of these standardized yellow glasses (nominally 35 and really not much different from 35).

A group of yellow glasses ranging from 0 to 10 (such as 2, 4, 6, 8, and 10).

A group of red glasses ranging from 0 to 20 (such as $0.1,0.2,0.3$, $0.4,0.5,0.6,0.7,0.8,0.9,1.0,2.0,3.0,4.0,7.0,12.0$, and 17.0).

Five zero glasses.

2. Match the oil with red and yellow glasses by trial and error, subject to the following conditions: 
(a) The added red must consist of a combination of not more than three red glasses.

(b) The added yellow (that is, in addition to the nominal $35 \mathrm{Y}$ glass) must consist of one glass only, this glass being added either to the oil or to the other glasses, whichever is needed to give a perfect match (that is, a saturation match as well as a hue match).

(c) The number of glass plates in each path should be constant during all observations, ${ }^{32}$ zero glasses being substituted for either red or yellow when they are removed..$^{33}$

(d) All judgments of match are to be made at (or near) a brightness match to be obtained by suitable instrumental adjustment.

3. Specify the quality of the color of the oil ${ }^{34}$ by $(a)$ the equivalent shown in yellow and red in Column II of Table 1 for the calibrated glass in question; $(b)$ plus the added red; $(c)$ plus or minus the added yellow, the plus sign applying if this yellow was added to the other glasses, and the minus sign applying if it was added to the oil.

Or, in symbols, the result will be-

where

$$
\left(N^{\prime \prime}+N\right) \mathrm{Y}+\left(n_{\mathrm{r}}+n\right) \mathrm{R}
$$

\section{$N^{\prime \prime}$ and $n_{\mathrm{r}}$ are taken from Column II of Table 1 ; and}

$N$ is the numeral of the added yellow glass (assuming it has no sensible "red correction"), $N$ being positive if added to the other glasses and negative if added to the oil sample; and

$n$ is the sum of the numerals of the added red glasses.

The above procedure takes care of specifying the quality of color (involving hue and saturation) but gives no information concerning brilliance, which depends upon the transmission of the oil. If it is desired to report the transmission of the oil, in addition to its color quality on the Lovibond scale, this may be computed by taking account of $(a)$ the transmission of the glasses, and $(b)$ the photometer (Martens) scale reading for brightness match. ${ }^{35}$

\footnotetext{
32 It may not be obvious, either in the standardization of Lovibond glasses or in the grading of oils as here outlined, why there is need for the use of zero glasses when a photometer is available for equating brightnesses. The purpose is to avoid the possibility of error, even though slight, introduced as a result of the multiple reflections that take place between the various surfaces. Any such error is avoided in the standardization of Lovibond glasses by keeping the number of glass plates combined with the standard equal to the number combined with the test glass.

However, in the grading of oils in terms of Lovibond glasses the experimental conditions under which the match is obtained must of neeessity be somewhat arbitrary, and there would be no point in specifying that the numbers of surfaces in the sample path and the glass path be equal. The scheme outlined keeps the number of reflecting surfaces constant in each beam for all oil samples and thus avoids any possibility of this error entering into the grading of one oil relative to another.

${ }^{33}$ This will mean that at the start there will be (1) on the oil side, one zero glass (to be replaced by yellow later if found necessary); and (2), on the glass side, the approximate $35 \mathrm{Y}$ glass with four zero glasses (one of which is to be replaced by yellow later if found necessary and three of which may be replaced by red).

${ }^{34}$ Quality takes account of both hue and saturation but not brilliance.

${ }_{85}$ To discuss this in detail would take us beyond the scope of the present paper, and the discussion would not be seasonable until the interested parties demand a report on transmission. We merely point out the possibility here.
} 


\section{B. Under Present Customary Conditions of Using the Glasses.}

Under these conditions it is to be expected that an observer who can detect a difference of $0.2 \mathrm{R}$ under favorable conditions will often make errors as large as $0.5 \mathrm{R}$ even with glasses accurately specified by their attached numerals. ${ }^{36}$.With the frequent occurrence of errors as large as $0.5 \mathrm{R}$ due to the method of using the glasses, it is plainly useless to apply corrections of only $0.1 \mathrm{R}$ and $0.2 \mathrm{R}$. Perhaps it would be advisable to use glasses having $n_{\mathrm{r}}$ (Column II, Table 1) greater than 0.2 (about 25 glasses of the 65) with some caution in critical cases where some refinement of the customary methods is used. Seven glasses (AOCS Nos. 27, 31, 41, 97, 119, 125, and 131) should likewise be regarded with suspicion under similar circumstances for reasons cited in detail in Column XII of Table 1 (see notes at foot of the table). ${ }^{37}$ But, under the present customary conditions of grading oils, all of the glasses, with the possible exception of three (AOCS Nos. 41, 97, and 119) whose surfaces are badly marred, may be regarded as practically equivalent to standard 35 yellow.

\section{GENERAL CONCLUSIONS}

1. It is clear (from the algebraic mean, foot of Column II, Table 1) that the average equivalent of these 65 glasses is not in precise accord with the standard 35 yellow derived by Priest and Gibson from the Bureau of Standards set (B. S. 9940) obtained from the Lovibond establishment. On the other hand, the discrepancy is certainly not more than two or three times the least difference perceptible with certainty by the best observers under the most favorable conditions of observation. ${ }^{38}$

2. Of course, if their own average were taken as standard instead of the standard arbitrarily adopted, the "errors" for most of the glasses would be notably decreased. With a very few possible exceptions, the uniformity of these glasses is quite as good as could be required or expected in order to comport with the purposes and methods of use for which they were intended by the makers. The

\footnotetext{
${ }^{36}$ Actual tests carried out in May, 1928, in connection with the convention of the A. O. C. 8. at New Orleans disclosed many such errors. A report on these tests is in preparation.

${ }^{37}$ The glasses having notably abnormal transmissions may be troublesome in instruments in which the fields are close together.

${ }_{88}$ The idea occurs that it might seem reasonable to adopt the average as standard instead of the standard which has been adopted. It must be remembered, however, that the present standard $35 Y$ is only ono of a series of standard yellow glasses (varying from 0 to 40 in Lovibond numeral) specined indirectly by the set of glasses (B. S. 9940) possessed by the Bureau of Standards. If the present standard 35Y be rejected in favor of a new standard, we must reject also the entire series of old standards; hence, there would be available no specifications by which departures from the new standard $35 \mathrm{Y}$ could be expressed. The logical way to use the average value of the present lot of nominal $35 \mathrm{Y}$ glasses as a factor in the specification of a new standard $35 \mathrm{Y}$ would be to investigate equally large numbers of yellow glasses of other grades and to redetermine standard specifications of the entire yellow scale. Such a plan is plainly unfeasible. Furthermore, the present standards undoubtedly approximate closely to those which would result from oarrying out such a plan.
} 
irregularities found and reported here have only been discovered by methods of observation greatly exceeding in sensibility and accuracy the methods of color matching contemplated by the makers and the methods actually used by the oil chemists in grading oils.

3. With the possible exception of three badly marred glasses, all of the glasses are considered fit to be regarded as equivalent to standard 35 yellow under the present customary conditions of grading oils..$^{39}$

4. An outstanding result of this investigation is the conclusion that the discrepancies of color grading which have troubled the oil trade can not be charged to lack of uniformity among the 35-yellow glasses. The sources of these troubles are rather to be sought in the following factors:

(a) Unstandardized, nonuniform, and insensitive rnethods of comparing the oil samples with the glasses.

(b) Grading of oil by observers having abnormal color sense or low power of hue discrimination.

(c) Errors in the red glasses.

It seems just to assume that this rather large collection of glasses constitutes a fair sample of 35-yellow glasses issued by the Lovibond establishment and in use in the oil trade in the United States. If this be admitted, it seems superfluous to test individual 35-yellow glasses further under present conditions. The chance of finding one with an error great enough to be of consequence in comparison with the other uncertainties just mentioned is very small. After the abovementioned sources of error have been eliminated in practice, it will be due season to reconsider the calibration of 35 -yellow glasses if it then appears necessary. In the meantime, it may well be considered legitimate to accept on faith the 35 -yellow glasses as issued by the Lovibond establishment.

Washington, August, 1927, to November, 1928.

${ }_{38}$ The point to this recommendation is not that the glasses are perfect from the point of view of precision calibration, but that the errors found are negligible in comparison with the uncertainties inherent in the customary methods of using the glasses. When more reliable and precise methods of grading are adopted, it will be in order to consider using the precise equivalents which are given for each glass. Of course, even under present conditions, the glasses which approach more nearly standard 35 yellow may, perhaps, be regarded with somewhat greater satisfaction and respect by those who use them. The detailed data given in Table 1 of the report will enable such glasses to be identified. 